\title{
Dad Jokes and the Deep Roots of Fatherly Teasing
}

\author{
Marc Hye-Knudsen \\ Department of English, Aarhus University
}

\begin{abstract}
Dad jokes, I argue, are a manifestation of the ancient fatherly impulse to tease one's children. On the surface, dad jokes are puns that are characterized by only violating a pragmatic norm and nothing else, which makes them lame and unfunny. Only violating a pragmatic norm and nothing else, however, is itself a violation of the norms of joke-telling, which makes dad jokes a type of anti-humor. Fathers (i.e., "dads") may in turn seek to embarrass their children by purposively violating the norms of joke-telling in this way, thus weaponizing the lame pun against their children as a type of good-natured teasing. Given their personality profile, it makes sense that fathers should be particularly prone to weaponize dad jokes teasingly against their children like this, with the phenomenon bearing an illuminating resemblance to the rough-andtumble play that fathers have engaged their children in since before the dawn of our species.
\end{abstract}

Keywords: dad jokes, puns, humor, anti-humor, teasing, benign violation, fatherhood, roughand-tumble play, evolutionary psychology

In recent years, dad jokes have gained increasing notoriety both as a concept and as a phenomenon, yet they remain poorly understood. In 2019, Merriam-Webster's Dictionary added an entry on dad jokes with the following definition: "a wholesome joke of the type said to be told by fathers with a punchline that is often an obvious or predictable pun or play on words and usually judged to be endearingly corny or unfunny." This definition raises a number of questions: Firstly, why is this type of joke specifically associated with "dads"? Are fathers actually more prone to employ them, and if so, why? Furthermore, how can we make sense of the popularity of dad jokes given that they are explicitly said to be "unfunny"? Even those definitions of the genre that do not specifically use the word "unfunny" include some reference hereto, instead calling them "lame" (Dictionary.com 2020), "hackneyed" (OED 2020), or "embarrassingly bad" (Urban Dictionary 2020). Yet, many if not most people must 
clearly find dad jokes funny in some sense since they continue to share them and to seek them out. On Reddit.com, the community r/DadJokes, which is specifically dedicated to sharing dad jokes, has a staggering 3.4 million members. Similarly, Google Books lists no fewer than 300 books solely dedicated to compiling examples of the genre, and the website Buzzfeed alone has an equal number of articles that are just lists of dad jokes. An exemplary dad joke from one such article goes like this: "A duck walks into a pharmacy and says, 'Give me some lip balm — and put it on my bill'" (Bullock 2015). Are dad jokes like this funny, unfunny, or somehow both? To answer such questions and to get to the bottom of the phenomenon of dad jokes, we have to look closer at the deep roots of both dads and jokes.

Taking a long view like this will allow us to bypass such common misunderstandings as the idea that dad jokes are simply bad jokes and that dads have a bad sense of humor. Drawing on the work of the psychologists Peter McGraw and Caleb Warren, which posits that humor is an evolved response to benign norm violations, I will here attempt to resolve in what sense dad jokes are funny and in what sense they are not. I argue that dad jokes have to be considered as functioning on at least three levels, namely as lame puns, as cases of antihumor, and as cases of weaponized anti-humor. As puns, I propose that dad jokes are characterized by only violating a pragmatic norm and nothing else, which makes them lame and unfunny. Only violating a pragmatic norm and nothing else, however, is itself a violation of the norms of joke-telling, which makes dad jokes a type of anti-humor. Fathers (i.e., "dads") may in turn seek to embarrass and/or annoy their children by purposively violating the norms of joke-telling in this way, thus weaponizing the lame pun against their children as a type of good-natured teasing. While not funny as lame puns in themselves, it is thus in their context as anti-humor and as weaponized anti-humor that dad jokes become funny. It is in this last context as weaponized anti-humor, in turn, that the connection between dads and dad jokes is to be found. Given their distinct personality profile, I argue that it makes sense that fathers should be particularly prone to weaponize dad jokes teasingly against their children, with the phenomenon bearing an illuminating resemblance to the rough-and-tumble play that fathers have engaged their children in since before the dawn of our species.

\section{The Origins of Dads, Jokes, and Dad Jokes}

To understand the nature of dad jokes, we first have to understand each of its constituent concepts: dads and jokes. Incidentally, the origin and nature of these two things, dads and jokes, are intimately tied together through their common link with rough-and-tumble play, which is the foundation from which humor has evolved. This requires some explication. 
Jokes are verbal or physical gestures meant to evoke the psychological response of humor, which is comprised of the positive emotion of amusement and the physiological tendency to laugh (Martin 2007). The humor response is a universal component in the human emotional repertoire, but what exactly is it about jokes that evokes this response in us? This question has been a source of debate among scholars for literally thousands of years, but a consensus seems to have emerged among contemporary humor scholars that humor at least requires the perception of "incongruity," something that is incongruous with our expectations or our normal mental patterns (see Morreall 2009). Many jokes, for instance, employ a setup/punchline-format wherein the "set-up" sets up an expectation that the punchline then incongruously violates (Ritchie 1999). This so-called "incongruity theory," however, is far too broad to satisfactorily account for the humor response: Why, for instance, is slipping on a banana peel commonly considered humorous while winning the lottery or being unexpectedly diagnosed with cancer is not, despite all three scenarios being both incongruously unexpected and atypical? To answer such questions, a more precise model of humor is required.

\section{Humor as an Evolved Response to Benign Violations}

The benign violation theory of humor, originally formulated by Thomas Veatch (1998) but significantly expanded upon by the psychologists Peter McGraw and Caleb Warren (2010), builds on the incongruity theory while offering much stricter conditions for the elicitation of humor. Firstly, the benign violation theory specifies that the violations necessary for humor must have a negative valence instead of simply departing incongruously from our expectations or our normal mental patterns; hence slipping on a banana peel is commonly considered humorous while winning the lottery is not. In other words, for something to be humorous it must violate not just our expectations of how things usually are but rather our normative sense of how they "ought" to be. In order for such a violation to elicit humor instead of purely negative emotions, however, the benign violation theory further specifies that it must ultimately be appraised as benignly non-worrisome; hence being diagnosed with cancer is not typically considered humorous either. For something to be humorous according to the benign violation theory, it must thus simultaneously be appraised as a violation (i.e., wrong, bad, or threatening) and benign (i.e., normal, harmless, or okay). Revising the incongruity theory by narrowing the definition of a violation and including the condition of benignity allows the benign violation theory more accurately to distinguish that which is humorous from that which is not. In numerous experiments, Warren and McGraw (2016) 
have demonstrated this by showing the benign violation theory to be more accurate in predicting humor than any other prominent conceptualization of incongruity.

The benign violation theory is an ideal analytical tool for understanding the phenomenon of dad jokes. By offering both necessary and sufficient conditions for humor, it will allow us to establish in what sense dad jokes are funny and in what sense they are not. In order for something to be funny, it must hit the sweet spot of both eliciting a violation appraisal and a benign appraisal. When a joke is unfunny (i.e., fails to elicit humor), it is either because it does not strike its recipient as being enough of a violation or as being ultimately benign. People may differ in what they find funny by virtue of differing in what they judge to be a violation and what they judge to be benign. To a prudish person, for instance, someone farting in their presence is undoubtedly a violation, but they may fail to find it benignly humorous. Someone with a less prudish disposition, however, may find it very humorous by virtue of seeing the violation as ultimately benign. In this way, the benign violation theory will allow us to explain why dads should be predisposed to find dad jokes humorous while their children should only find them embarrassing or annoying by reference to the distinct temperamental and emotional dispositions of these two groups. Moreover, the benign violation theory is ideal for understanding dad jokes in that it illuminates the connection between humor and the rough-and-tumble play that fathers have been known to engage with their children in since before the dawn of our species. Biologists have long known that humor likely evolved from rough-and-tumble play, but the benign violation theory highlights the marked continuity between the two.

Humorous laughter, biologists have argued, is likely to have originated as a "play signal" with an apparent antecedent manifested in the distinctly laugh-like panting vocalization that accompanies the play face of some of our closest related primates like chimpanzees (van Hoof 1972; Provine 2000; Polimeni and Reiss 2006). Many mammals, including primates like chimpanzees, form social bonds and learn vital skills through social play, which most often takes the form of play-fighting (i.e., "rough-and-tumble play"). During such play, the participants will play at physically violating each other's boundaries by wrestling, chasing, biting, fleeing, and the like. Here, play signals like the play face and its accompanying panting serve to indicate that all physical violations are intended and construed as benign, thereby ensuring that no misunderstandings occur that could accidentally escalate the play-fighting into actual violence (Gervais and Wilson 2005). The play face, moreover, is presumably accompanied by some kind of amusement-like positive affect that spurs on further play. The first violations to have elicited laughter and 
"protohumor" are thus thought to have been the benign physical violations that constituted the rough-and-tumble play of early humans (McGraw and Warren 2010, 1142). In turn, the benign violation theory posits that during the course of our evolutionary trajectory the situations capable of eliciting humor were gradually expanded to include other kinds of violations, like linguistic norm violations (e.g., puns and wordplay), social norm violations (e.g., farting in public), and moral norm violations (e.g., black humor).

The link between humor and rough-and-tumble play is illuminating. Rough-andtumble play is an avenue through which young primates learn vital physical skills that they will use later in life (Boyd 2004). By playing at fighting, chasing, fleeing, and the like, chimpanzees are better prepared to do so for real when the time comes. As an adult, failure at any of these tasks could be fatal. Rough-and-tumble play is also a vital part of childhood for members of our own species (Bokony and Patrick 2009). By playing at physically violating the boundaries of others and by playfully having their own boundaries violated, children learn to handle aggression, they learn what their own bodies can endure, and they learn what actions they can perform on others without hurting them, among other things. But the physical skills associated with activities like fighting are far from sufficient to get by as a member of our species. Humans, as some evolutionary researchers have put it, occupy a "cultural niche" (Boyd, Richerson, and Henrich 2011). To get by as a Homo sapiens, we have to absorb an extensive set of culturally specific linguistic, social, and moral norms from the people around us. One way we do this is through humor. By playing at violating the linguistic, social, and moral norms of our culture, and by witnessing others playfully violate them, we gain acquaintance both with the norms themselves and with their exceptions, those cases in which their violations are thought harmless enough to laugh at (Simler and Hanson 2017, 129-48). In this respect, humor resembles its predecessor, rough-and-tumble play.

\section{Dads as Playmates and Jokers}

Every individual human being has to internalize the extensive and intricate set of norms that constitutes their culture. That is part of the reason why we have such exceptionally long childhoods compared to other species (Fuentes 2017). We need time to master our culture, and we do this in great part through play and humor. Of course, neither play nor humor is restricted to childhood, but a great part of childhood consists of playing and joking around. In fact, among contemporary nomadic hunter-gatherers, whose lifestyle is thought to resemble that of our ancestors for most of human history, children spend almost all of their time playing and joking around (Gray 2009). The fact that our childhoods are so exceptionally 
long, in turn, was a central driver behind the evolution of fatherhood in humans. Among the primates closest related to us, males are almost entirely uninvolved in the upbringing of their offspring-except, interestingly, when it comes to rough-and-tumble play. Chimpanzee fathers spend more time playing with their own offspring than they do with unrelated young (Boesch, Lehmann, and Fickenscher 2006; Carson et al. 2016). With this exception, however, they remain largely uninterested in their offspring (see Geary 2000). This is not the case with human fathers. Due to their slow maturation and extended childhood, human children impose a burden on their mothers so heavy that it makes investment from others necessary. The remarkable degree of paternal care in our species is a result (Bjorklund and Shackelford 1999; Hrdy 2009). Yet, human fathers still remain less involved than mothers on average in all aspects of child-rearing, with one very telling exception: rough-and-tumble play (Bokony and Patrick 2009).

The distinct personality profile of fathers makes them ideally suited for engaging their children in rough-and-tumble play. Both fathers and mothers play with their children, but fathers are more physical and challenging in their play (Paquette et al. 2003). Fathers' play is typically more vigorous and unpredictable than mothers' play, and they tend to push their children to the limits of what they can handle, encouraging them to fight harder, run faster, climb higher, and the like (Bokony and Patrick 2009). This difference between fathers and mothers as playmates can be attributed to men's greater physical strength, their higher levels of physical aggression and assertiveness, and their lower levels of agreeableness and neuroticism as compared to women (Costa, Terracciano, and McCrae 2001; McCrae et al. 2005; Weisberg, DeYoung, and Hirsh 2011; Björkqvist 2018). While men's greater physical strength, aggression, and assertiveness likely pushes fathers to be rougher and more challenging in their play, women's higher levels of agreeableness and neuroticism may in turn impede mothers in this regard for fear of accidentally hurting their child. Evolutionarily, all of these sex differences have been traced to women's greater investment in each offspring. Women's greater parental investment has been the source of intrasexual competition among men, which has likely selected for traits that are useful for conflict, including the physical kind, i.e., physical strength, aggression, and assertiveness (Buss 2016, 290-314). On the other hand, women's greater parental investment has likely selected for nurturing traits in themselves, i.e., agreeableness (empathic concern, consideration, kindness) and neuroticism (anxiety, worry, sensitivity to negative emotion), useful qualities for caring for a child and protecting it from potential harms (Campbell 2002; Alvergne, Jokela, and Lummaaa 2010). 
The personality traits that cause fathers' more physical and aggressive style of play also give them a distinct style of joking with their children. Both fathers and mothers joke with their children, but fathers are more challenging and teasing in their humor (Bokony and Patrick 2009). Teasing is perhaps the type of joking that most directly reflects the origins of humor in rough-and-tumble play. Instead of quasi-violent mock aggression, which is the basis of rough-and-tumble play, teasing is based on all kinds of mock aggression. Teasing often takes the form of playfully provocative verbal statements that are meant to benignly strike at the recipient's feelings (as distinct from bullying, where the purpose is primarily domination instead of affiliative humorous amusement [Keltner et al. 2001]). Yet, teasing need not be verbal, and teasing behaviors have been observed both in preverbal infants and in non-human primates (Eckert, Winckler, and Cartmill 2020). Non-verbal examples of teasing include offer and withdrawal (e.g., offering an object to someone and then quickly pulling it away as they reach for it) and playfully disrupting others' activities (e.g., taking an object from someone that they are engaging with). Just as men's higher levels of aggression and assertiveness spurs them to be more aggressive and provocative in their play, so too it is likely what spurs them to be more aggressive and provocative in their humor. On the other hand, women's higher levels of agreeableness and neuroticism, which impede them from being aggressive in their play from fear of hurting their child physically, is likely also what impedes them from teasing their children from fear of hurting them emotionally.

At first blush, fathers' style of play might seem harsh and unkind as compared to mothers', but that would be a misunderstanding. Children's pleasure in rough-and-tumble play is actually most intense when they play with fathers because they are rougher and wont to challenge them more (Paquette et al. 2003). Moreover, rough-and-tumble play with fathers has been shown to have numerous positive effects, supporting children's physical and cognitive development while teaching them to regulate their behaviors and emotions (Flanders et al. 2009; StGeorge and Freeman 2017). Ideally, fathers' rougher style of joking fulfills a similar function: By teasingly striking at their children's egos and emotions without teetering over into bullying, fathers build their children's resilience and train them to withstand minor attacks and bouts of negative emotion without getting worked up or acting out, teaching them impulse control and emotional regulation (see Gray 2013). Moreover, the function of play and humor is not just education but also bonding (Gervais and Wilson 2005). Both play-fighting and teasing are thus ways in which fathers bond with their children even as they push them to the limits of what they can handle. I contend that dad jokes are a 
manifestation of fathers' impulse to teasingly challenge and provoke their children like this. That might sound counterintuitive since dad jokes, at their most basic level, are simply lame puns, seemingly the least provocative type of humor there is. Dad jokes, however, are much more than this. To understand how dad jokes constitute a type of teasing, in turn, we have to examine each of the levels on which they work as jokes.

\section{Dad Jokes as Lame Puns}

Not all puns are dad jokes, but virtually all dad jokes are puns. This is acknowledged by everyone who has concerned themselves with the joke genre at length in popular magazine articles or the like (Fetters 2018: Geary 2018; Luu 2019; Zinoman 2019; Mitchell 2019). In order to understand how dad jokes work and why dads are predisposed to engage in them, we first have to understand what sets apart the puns that qualify as dad jokes from the puns that do not. Puns have long had a bad reputation as a low and unwitty form of humor (Redfern 2000), but the puns that qualify as dad jokes are distinguished by a specific quality that makes them particularly susceptible to accusations of badness, lameness, and unfunniness. It will not be necessary here to recapitulate the vast and extensive literature on the linguistic features of puns and their underlying mechanisms (for a review hereof, see Hempelmann and Miller 2017). For the purposes of this paper, it will be sufficient to note that puns are a type of verbal humor that exploit the fact that a sound sequence (e.g., a word or phrase) has two meanings. Consider the pun from the introduction to this paper: "A duck walks into a pharmacy and says, 'Give me some lip balm - and put it on my bill'” (Bullock 2019). Here, it is, of course, the deliberate double meaning of the phrase my bill that constitutes a pun. The pun requires its listener to realize the first possible meaning of the phrase, the second possible meaning, and the tension between the two (see Attardo and Raskin 1991).

What is it, exactly, that puns like this benignly violate to humorous effect? As Raskin and Attardo (1994) have argued, puns, like many kinds of verbal humor, violate the "cooperative principle" of conversational communication. As first documented by the linguist Paul Grice (1975), the cooperative principle refers to the implicit pragmatic norms that allow conversational communication to unfold effectively. In fact, Michael Tomasello (2010) has argued that these implicit norms were a prerequisite for human language to evolve in the first place. Specifically, puns violate the norm of conversational communication that prohibits intentional ambiguity (Aarons 2017, 81). To make sense of each other's contributions, it is essential for participants in normal human conversation to be able to trust that their partner 
will only ever say one thing at a time, with their words thus having a clear, unambiguous meaning. With a pun, the speaker violates this conversational norm by purposively saying two different things at the same time, with their words thus having multiple and sometimes contradictory meanings. Thus, puns violate the implicit contract that makes human communication possible. Typically, the speaker will signal that this violation is meant to be benignly playful through a shift in tone, through their facial expression (e.g., a sly smile), or through the use of discursive cues (e.g., "Have you heard the one about...?"). Puns are thus a way of playing around with using language "wrongly" (Warren and McGraw 2016), benignly violating its rules of usage in conversational communication to humorous effect, at least in principle.

Yet, few people are strongly enough committed to the pragmatic norms of everyday conversation for their breach to register as much of a violation in itself; hence puns lack force as humorous stimuli and are typically considered a stale form of humor (Beck 2015). When people violate the pragmatic norm against ambiguity by employing a pun, it is consequently often in the service of benignly violating another norm of some kind that is capable of provoking more of a response. For instance, social norms dictate what kind of language is appropriate when and where, prohibiting the use of certain "dirty" words pertaining to sexuality in polite company (Pinker 2008, 323-72). A sexual pun allows the speaker to violate these norms in one sense while in another sense benignly complying with them. Mel Brooks provides an example in his film History of the World: Part 1 (1981), wherein he plays an ancient Roman who remarks that "we've got a god for everything. The only thing we don't have a god for is premature ejaculation . . . but I hear that it's coming quickly." In one sense, this is an innocuous remark about the fact that a god for premature ejaculation is about to join the Roman pantheon, but "coming quickly" can of course also be understood as an inappropriately crude way of referring to premature ejaculation itself. As a sexual pun, this is thus not just a violation of a pragmatic norm but also a social one. Similarly, dark puns like dead baby jokes violate the social norms that limit which sensitive subjects can be joked about (Dundes 1979). An example is the following pun, which plays on the ambiguity of the word abort: "I was going to tell a dead baby joke, but then I decided to abort" (Okafur 2019).

The distinguishing characteristic of dad jokes is that they are puns that are only puns - which is to say, they are puns that only violate the pragmatic norm against ambiguity and nothing else (see table 1). This is why they are often described as "wholesome" (Merriam-Webster 2019), “inoffensive” (Urban Dictionary 2020), “clean” (Kort 2020), or 
Title of book or article

First included example of a dad joke

\begin{tabular}{|c|c|}
\hline $\begin{array}{l}\text { Dad Jokes: The Cheesy Edition } \\
\text { (Dad Says Jokes 2020) }\end{array}$ & $\begin{array}{l}\text { "My neighbor tiled my roof for free. He said it was } \\
\text { on the house." }\end{array}$ \\
\hline $\begin{array}{l}\text { World's Greatest Dad Jokes } \\
\text { (Brueckner 2019) }\end{array}$ & "Did you year the joke about paper? It's tear-able." \\
\hline $\begin{array}{l}\text { The VERY Embarrassing Book of } \\
\text { Dad Jokes (Allen 2012) }\end{array}$ & $\begin{array}{l}\text { "Why did the orange stop halfway up the hill? He } \\
\text { ran out of juice." }\end{array}$ \\
\hline $\begin{array}{l}\text { The Essential Compendium of Dad } \\
\text { Jokes (Nowak 2020) }\end{array}$ & $\begin{array}{l}\text { "In my career as a lumberjack, I've cut exactly } 2,325 \\
\text { trees. Every time I chop one down, I keep a LOG." }\end{array}$ \\
\hline $\begin{array}{l}\text { Dad Jokes! Good, Clean Fun for } \\
\text { All Ages! (Niro 2018) }\end{array}$ & $\begin{array}{l}\text { "'Dad, will you hand me my sunglasses?'. 'As soon } \\
\text { as you hand me my dadglasses, Son."” }\end{array}$ \\
\hline $\begin{array}{l}\text { “63 Best Dad Jokes Guaranteed to } \\
\text { Make You Giggle” (Donavan 2020) }\end{array}$ & $\begin{array}{l}\text { "'Dad, did you get a haircut?'. 'No, I got them all } \\
\text { cut!"” }\end{array}$ \\
\hline $\begin{array}{l}\text { “70 Best 'Dad Jokes’ for 2020” } \\
\text { (Athlon Sports 2020) }\end{array}$ & $\begin{array}{l}\text { "What did the drummer call his twin daughters? } \\
\text { Anna one, Anna two!" }\end{array}$ \\
\hline $\begin{array}{l}\text { “105 Dad Jokes So Bad They're } \\
\text { Actually Hilarious” (Larkin 2020) }\end{array}$ & $\begin{array}{l}\text { "What do sprinters eat before a race? Nothing, they } \\
\text { fast!" }\end{array}$ \\
\hline $\begin{array}{l}\text { "Here are the } 100 \text { Best Corny Dad } \\
\text { Jokes Ever!" (Pelzer 2020) }\end{array}$ & $\begin{array}{l}\text { "Which bear is the most condescending? A pan- } \\
\text { duh!" }\end{array}$ \\
\hline $\begin{array}{l}\text { "The Big List of the Funniest Dad } \\
\text { Jokes" (Webber 2020) }\end{array}$ & $\begin{array}{l}\text { "To whoever stole my copy of Microsoft Office, I } \\
\text { will find you. You have my Word!" }\end{array}$ \\
\hline
\end{tabular}

Table 1: There are countless books and articles solely dedicated to compiling examples of dad jokes. This table displays the very first example of a dad joke included in ten different such books or articles. As apparent from this selection, dad jokes are distinguished by being inoffensive puns that only violate the pragmatic norm against ambiguity and nothing else.

even "squeaky-clean" (Fetters 2018). The fact that dad jokes inoffensively shy away from violating anything other than the pragmatic norm against ambiguity is what allows dads to tell them around children in a dinner table setting, but it is also what makes them so susceptible to accusations of badness, lameness, and unfunniness. As already noted, most people are not committed enough to the pragmatic norms of everyday conversation for their breach to strike them as enough of a violation to merit the humor response. However, this is different for young (preadolescent) children who are still getting acquainted with the rules 
governing language and conversational communication, for whom the violation of these rules may seem more pungent and therefore more humorous (Schulz and Horibe 1974; McGhee 1979; Semrud-Clikeman and Glass 2010). Thus, it seems plausible that dads start telling wholesome puns to their children while they are still young enough to earnestly enjoy them (peaking around age 7). However, there is no reason that fathers should be more predisposed towards doing this than mothers. As such, it is not here that the particular association between dads and dad jokes is to be found. Rather, this only comes about once the child matures and begins, like most people, to see wholesome puns as a lame type of humor.

\section{Dad Jokes as Anti-Humor}

Despite the fact that dad jokes are stereotypically considered bad, lame, and unfunny by adults, many if not most must clearly still find them funny in some sense since they continue to seek them out, to share them, and even to laugh at them. One commentator describes dad jokes as jokes that you "hate [your]self for laughing at," jokes that "have no right to be as hilarious as they are" (Martinez 2020). There's an entire genre of viral video wherein two people (often celebrities) read dad jokes aloud to each other in a competition to see who can refrain from laughing. In these videos, the participants typically fail continually at holding back laughter even while chastising the jokes they are laughing at for being bad. For instance, the actors Will Ferrell and Mark Wahlberg, in a video from 2017 on the YouTube channel All Def, laugh themselves red-faced at the dad jokes they read to each other even while continually describing them as "bad," "stupid," and "terrible." Yet, their disparaging comments about the jokes they are laughing at only make them laugh harder. This points to the counterintuitive mechanism behind the appeal of dad jokes for adults: The fact that they are spectacularly unfunny is paradoxically what makes them funny. This makes dad jokes a type of anti-humor (Luu 2019). As the philosopher Warren Shibles defines the phenomenon, anti-humor "creates humor by not creating humor" (1997). To appreciate the appeal of dad jokes for adults, we thus have to consider them from a meta-perspective as humor that plays around with the norms surrounding humor itself.

In essence, anti-humor is humor derived from benignly violating the norms of humor production. As I have already recounted, verbal humor often relies on violating those foundational pragmatic norms governing everyday conversation that Paul Grice collectively dubbed "the cooperative principle." As Raskin (1992) has argued, however, a different set of pragmatic norms seem to govern humorous discourse. The principle norm is this: When we 
switch to the humorous mode of discourse, it is because we have something funny to say. Often, we signal our switch to the humorous mode of discourse through the gestures I have previously described, i.e., through a shift in tone, a sly smile, or the use of discursive markers like "Have you heard the one about ... .?". If these gestures are not followed by something sufficiently funny to warrant the switch, then that is a violation of the norms of humor production. This very violation, however, may itself evoke humor, thus paradoxically vindicating the switch to the humorous mode. One common form of anti-humor, for instance, are anti-jokes that follow the classic question/answer-format but without a humorous answer, e.g., "What do you call a joke that isn't funny? A sentence" (Larkin 2019). The letdown of the answer here, which is factual instead of funny, is itself what is supposed to be funny. This is also how dad jokes work: Telling a lame pun that only violates the pragmatic norm against ambiguity and nothing else is itself a violation of the norms of joke-telling in that the lame pun is not sufficiently funny to warrant being told. Yet, this paradoxically makes it funny.

In principle, a dad joke can violate the norms of joke-telling to benignly humorous effect in this way even if that is not the intention of the joke teller. Sometimes, the figure of a cluelessly unfunny father is invoked in discussions of dad jokes, a clownish character who inadvertently evokes humor at his own expense by spectacularly failing in his earnest attempts at telling genuinely humorous jokes. Ian Allen is the author behind a popular series of books that compile examples of dad jokes, and the subtitles of all of his books reference this idea: "Because your dad thinks he's hilarious" (2012), "Because Dads aren't as funny as they think they are" (2013), and "Because Dads don't know when to stop" (2015). According to this conception of the phenomenon, dad jokes would be akin to films that are "so-badthey're-good" like Tommy Wiseau's iconically awful The Room (2003), a film where most audiences' enjoyment lies in appreciating how spectacularly its director has failed at living up to the norms of Classical Hollywood Cinema (Hye-Knudsen and Clasen 2019). In this case, the recipients of dad jokes would have to decouple empathically from the unfunny dad in order to find his earnest failure at humor production benignly humorous (Hye-Knudsen 2018). Presumably, the unfunny dad in question would not find his own failed attempt at humor funny - that is, unless he was so clueless as to not understand the fact that his audience is laughing at him instead of with him. The fact that fathers, at least traditionally, are expected to be stolid figures of patriarchal authority would only add to the humor here by making the loss of face even starker. However, there is good reason to doubt this idea of dads as clueless, unwilling fools. Instead, it would appear that they are very much in on the joke. 
Not only do the dads that tell dad jokes seem to be aware that their jokes are bad, they even seem to revel in it. This is made explicit by Allen himself in his first compilation of dad jokes, which opens with these words: "Let's get one thing straight from the start. Dad jokes aren't meant to be funny" (2012). As the linguist Chi Luu puts it, "dad jokes seem to court failure" (2019). In effect, they are invitations for the audience to laugh not at the joke itself but rather at its badness and thus, by extension, at its teller. According to Allen, "The perfect dad joke should generate groans not guffaws ... and pitying glances not affectionate smiles" (2012). This sentiment is mirrored by other compilers of dad jokes who almost invariably put words like "bad" (Norton 2020), "stupid" (Shifrin 2018), “embarrass[ing]" (Niro 2020), or "cringe" (Duran 2020) in their titles. In this sense, dad jokes require their teller to be willing to deliberately take on the role of the clown, to embarrass themselves for the sake of the humor this brings about. In theory, this might help explain why fathers should be more prone than mothers towards telling them since women's greater neuroticism could be thought to inhibit them from courting embarrassment in this sense. However, women in general do not seem any less prone to self-deprecating humor than men (Hofmann et al. 2020). As such, this explanation is less than satisfying. To understand why dads should be more prone towards making dad jokes and finding them funny, I propose that we have to look instead at who are wont to not find them funny, namely their children once they reach a certain age.

\section{Dad Jokes as Weaponized Anti-Humor}

For a dad joke to be enjoyed as anti-humor, its central social violation of the norms of joketelling must ultimately be appraised as benignly non-worrisome. Its teller must be able to withstand the potential embarrassment and social judgement that comes from telling a bad joke, i.e., the "groans" and the "pitying glances" it may inspire, as Allen has it (2012). Similarly, the audience of a dad joke have to be able to withstand the vicarious embarrassment of hearing a manifestly awful joke told with unbridled confidence if they are to find it humorous. This may be asking too much for one group in particular, namely children who are approaching or have entered that precarious stage of life termed adolescence. Adolescence is defined as the transitory stage between childhood and adulthood, lasting from the onset of puberty and until the achievement of relative self-sufficiency (Backes and Bonnie 2019). It is incumbent upon the adolescent to try to establish an identity for themselves as they navigate an increasingly complex social world, and accordingly it appears to be a particularly sensitive period for sociocultural processing (Blakemore and 
Mills 2014). Adolescents are famously sensitive to embarrassment, particularly vicarious embarrassment in relation to their parents, whom they are in the gradual process of decoupling from to establish an independent identity for themselves (Pickhardt 2013). As such, children go from being the prime audience for wholesome puns, when they are still young enough to earnestly enjoy them, to being likely instead to find them mortifyingly embarrassing as they approach adolescence (around ages 9-13).

This, I contend, is the true explanation for the link between dads and dad jokes. Since their adolescent or near-adolescent children are wont to find them embarrassing instead of humorous, fathers can weaponize lame puns against their children as a type of gentle teasing, which fits in with their generally more aggressive and ribbing style of joking. Whereas both mothers and fathers are wont to tell wholesome puns to their children while they are still young enough to earnestly enjoy them, fathers are thus more likely to obstinately keep telling them once their children near adolescence and begin to find them intensely embarrassing. The child's embarrassment of hearing their father tell a bad joke is compounded by the insult of having a childishly lame joke directed at them. This is an especially salient insult for adolescent children, who are actively engaged in the process of shedding their childish identities. The fact that dads utilize dad jokes as a weapon to tease their children is referenced in the title of many of the books and articles that compile examples of the genre, e.g., "15 Stupid-Funny Dad Jokes You Can Use To Embarrass Your Kids" (Romas 2014), Dad Jokes for New Dads: Embarrass Your Kids Early! (Niro 2020), or Dad Jokes: 60 Dad Jokes That Will Make Your Kids Cringe (Duran 2020). The propensity for fathers to employ dad jokes teasingly in this way can be attributed to the same male personality traits that cause them to be rougher generally in both their play and humor as compared to mothers, i.e., their greater aggression and assertiveness together with their lesser agreeableness and neuroticism. That the propensity for telling dad jokes is connected with the male psyche is attested to by the concept's analogues in other languages, which usually associate the phenomenon with men of a certain age if not with fathers directly (Luu 2019). The Japanese, for instance, have oyaji gyagu ("old men's gags") and the Danish have onkel humor ("uncle humor").

At first glance, the propensity of fathers to employ dad jokes teasingly against their children might seem cruel, in the same way that the male style of rougher play and humor in general can seem cruel to the uninitiated. Yet, this would be missing the point. Just as the harsh style of male rough-and-tumble play among humans and other primates serves to 
prepare children for the harsh world they will later face as adults, so too dad jokes can have a positively edifying effect on the very children that loathe them. As one dad perceptively puts it:

I think it's important to embarrass your kids. Or, to be more specific, I think it's important to do things traditionally viewed as embarrassing until your kids are basically immune to the effects. After years and years of being exposed to eye-roll inducing humor, with a complete disregard for what anybody else thinks, kids will have nothing greater left to fear. They'll gradually build up a strong immunity to judgement and embarrassment, and actually feel empowered to be themselves (Billingsley 2019).

This is a kind of intellectualizing explanation that few of the dads who employ dad jokes would be capable of formulating, but it fits with what we know of humor from an evolutionary perspective. Humor is a medium through which we acculturate ourselves and learn not only the norms of our culture but also their exceptions, when and in what circumstances they can be violated with impunity. Adolescents are infamously fearful of the embarrassment that can come from violating social norms. Through repeatedly exposing them to bouts of embarrassment with their dad jokes, dads can gradually tear away at this fear, teaching them not to take themselves so seriously.

Neither the dads who make dad jokes nor the children who loathe them are wont to understand any of this, at least not explicitly. Fathers are simply moved by their characteristically male personality traits to tease and challenge their children, pushing against the limits of what they can handle when joking with them. In doing so, they are acting on the same impulse that has moved fathers to push and challenge their children in rough-andtumble play since before the dawn of our species. Fathers' harsher rough-and-tumble play prepares children for the harsh physical challenges they will face later in life. Embarrassing dad jokes, in turn, prepare adolescent children for the social challenges they will face in adulthood, specifically the social challenge of being true to themselves and making confident, authentic choices despite the social judgement that can come from this. In contemporary Western culture, which rewards individualism over traditional conformity (Henrich 2020), the ability to withstand the embarrassment and social judgement that comes from violating social norms is a useful skill. As such, dad jokes are a form of fatherly teasing perfectly fitted to the age. This may not be appreciated by their children in the short term, but in time, 
perhaps when they themselves become fathers, they too will feel the impulse to tease those they love. In due time, they may thus come to appreciate that dad jokes are a manifestation of the fatherly love and care that is so peculiarly abundant in our species. As one commentator puts it, "Is a dad even a dad if he doesn't embarrass [his] kids?" (Daw 2018).

\section{Conclusion}

While dad jokes themselves may not be an ancient phenomenon, they are the product of inclinations that go back millions of years. Taking an evolutionary view of cultural phenomena like dad jokes is valuable in allowing us to see how even such a peculiar trend as this has deep and revealing roots, stretching far back into human prehistory to when the ancestral fathers of our lineage first started challenging and pushing their children in roughand-tumble play. A proper understanding of dad jokes must recognize both what it means to be a father in our species and what makes a joke successful or unsuccessful in evoking humor. Taking the evolutionary roots of joking and the personality profile of fathers into consideration allows us to bypass such common misunderstandings as the idea that dad jokes are simply bad jokes or that fathers simply have a bad sense of humor. While only being lame puns on the surface level, dad jokes have to be considered as working on two additional levels beyond this, namely as anti-humor and as weaponized anti-humor. The particular association between dads and dad jokes is to be found in this last context of theirs as weaponized anti-humor, an aspect of the phenomenon that has so far been left out of most dictionary definitions of dad jokes. Moreover, an appreciation for the evolutionary origin and functions of humor and teasing allows us to see how dad jokes come from a place of fatherly love even when they are purposefully aimed at embarrassing their teller's children. Ideally, they might even serve a beneficial function in toughening up the joke-teller's adolescent children to the sensation of embarrassment. All of these insights are only made possible by taking dad jokes seriously in considering their ancient roots. 


\section{Works Cited}

Aarons, Debra. 2017. "Puns and Tacit Linguistic Knowledge. In The Routledge Handbook of Language and Humor, edited by Salvatore Attardo, 80-94. New York: Routledge. All Def. 2017. "Dad Jokes I You Laugh, You Lose I Will Ferrell vs. Mark Wahlberg I All Def.” YouTube Video, 6:03, November 8, 2017. https://www.youtube.com/watch?v=SAgYiERRDPY\&list=PLasQL7SKWjcfgcbK813 f5Pm5QXMTJukIr\&ab_channel=AllDef.

Allen, Ian. 2012. The VERY Embarrassing Book of Dad Jokes: Because Your Dad Thinks He's Hilarious. London: Portico Books.

_. 2013. Bad Dad Jokes: Because Dads Aren't as Funny as They Think They Are. London: Portico Books.

- 2015. Crap Dad Jokes: Because Dads Don't Know When to Stop. London: Portico Books.

Alvergnea, Alexandra, Markus Jokela, and Virpi Lummaa. 2010. "Personality and LongTerm Reproductive Success Measured by the Number of Grandchildren.” Proceedings of the National Academy of Sciences 107 (26):11745-50. doi:10.1073/pnas.1001752107.

Athlon Sports. 2020. “70 Best 'Dad Jokes’ for 2020.” Athlon Sports, January 1, 2020. https://www .athlonsports.com/dad-jokes.

Attardo, Salvatore and Victor Raskin. 1991. "Script Theory Revis(it)ed: "Joke Similarity and Joke Representation Model." Humor: International Journal of Humor Research 4 (3/4): 293-347. doi:10.1515/humr.1991.4.3-4.293.

—. 1994. "Non-Literalness and Non-Bona-Fide in Language: An Approach to Formal and Computational Treatments of Humor." Pragmatics and Cognition 2 (1): 31-69. doi:10.1075/pc.2.1.02ras.

Beck, Julie. 2015. “Why Do Puns Make People Groan?” The Atlantic, July 10, 2015. https://www .theatlantic.com/technology/archive/2015/07/why-do-puns-make-peoplegroan $/ 398252 /$.

Billingsley, Ryan. 2019. "The Best Dad Jokes: A Little Embarrassment Is Good for You.” Dad Suggests, June 16, 2019. https://www.dadsuggests.com/home/the-best-dad-jokes. Bjorklund, David F., and Todd K. Shackelford. 1999. "Differences in Parental Investment Contribute to Important Differences Between Men and Women." Current Directions in Psychological Science 8 (3): 86-89. doi:10.1111/1467-8721.00020. 
Björkqvist, Kaj. 2018. “Gender Differences in Aggression.” Current Opinion in Psychology 19: 39-42. doi:10.1016/j.copsyc.2017.03.030.

Blakemore, Sarah-Jayne, and Kathryn L. Mills. 2014. "Is Adolescence a Sensitive Period for Sociocultural Processing?” Annual Review of Psychology 65 (1): 187-207. doi:10.1146/annurev-psych-010213-115202.

Bokony, P. \& Patrick, T. 2009. "What the Experts Say: Rough-and-Tumble Play." University of Arkansas for Medical Sciences. https://www.ucy.ac.cy/nursery/documents/Agrio_Pexnidi_sta_Nipia.pdf.

Bonnie, Richard J., and Emily P. Backes. 2019. The Promise of Adolescence: Realizing Opportunity for All Youth. Washington, DC: The National Academies Press. doi:10.17226/25388.

Boyd, Brian. 2004. "Laughter and Literature: A Play Theory of Humor.” Philosophy and Literature 28 (1): 1-22. doi:10.1353/phl.2004.0002.

Boyd, Robert, Peter J. Richerson, and Joseph Henrich. 2011. "The Cultural Niche: Why Social Learning is Essential for Human Adaptation." Proceedings of the National Academy of Sciences 108, suppl. 2: 10918-25. doi:10.1073/pnas.1100290108.

Brooks, Mel, dir. 1981. History of the World Part 1. Los Angeles, CA: 20th Century Fox. Brueckner, John. 2019. World's Greatest Dad Jokes: 160 Hilarious Knee-Slappers and Puns Dads Love to Tell. Kennebunkport, ME: Appleseed Press Book Publishers LLC. Bullock, Steve. 2019. "15 Dad Jokes That Are Just as Groan-Worthy As They Are Funny." Buzzfeed. September 9, 2019. https://www.buzzfeed.com/stevebullock/dad-jokes-thatare-just-as-groan-worthy-as-they-are-funny.

Buss, David. 2016. Evolutionary Psychology: The New Science of the Mind. 5th ed. London/New York: Routledge.

Campbell, Anne. 2002. A Mind of Her Own: The Evolutionary Psychology of Women. Oxford: Oxford University Press.

Costa, Paul T., Antonio Terracciano, and Robert R McCrae. 2001. "Gender Differences in Personality Traits across Cultures: Robust and Surprising Findings.” Journal of Personality and Social Psychology 81 (2): 322-31. doi:10.1037//0022-3514.81.2.322. Dad Says Jokes. 2020. Dad Jokes: The Cheesy Edition. London: Octopus Publishing Group. Daw, Dena. 2018. "20 Dads Who Had Zero Problems Embarrassing Their Daughters." TheThings, June 11, 2018. https://www thethings.com/20-dads-zero-problemsembarrassing-daughters/. 
Dictionary.com. 2020 “Dad Joke.” Dictionary.com. Accessed November 25, 2020. https://www .dictionary.com/browse/dad-joke.

Donavan, Blair. 2020 ، “63 Best Dad Jokes Guaranteed to Make You Giggle.” CountryLiving, July 28, 2020. https://www.countryliving.com/life/a27452412/best-dad-jokes/.

Dundes, Alan. 1979. "The Dead Baby Joke Cycle.” Western Folklore 38 (3): 145-157. doi:10.2307/1499238

Duran, Lorenzo. 2020. Dad Jokes: 60 Dad Jokes That Will Make Your Kids Cringe. Independently Published.

Eckert, Johanna, Sasha L. Winkler, and Erica A. Cartmill. 2020. “Just Kidding: The Evolutionary Roots of Playful Teasing.” Biology Letters 16 (9): 20200370. doi:10.1098/rsbl.2020.0370.

Fetters, Ashley. 2018. "What Makes a Dad Joke?” The Atlantic, September 25, 2018. https://www .theatlantic.com/family/archive/2018/09/deconstructing-the-dadjoke/571174/.

Flanders, Joseph L., Vanessa Leo, Daniel Paquette, Robert O. Pihl, and Jean R. Séguin. 2009. "Rough-and-Tumble Play and the Regulation of Aggression: An Observational Study of Father-Child Play Dyads.” Aggressive Behavior 35 (4): 285-95. doi:10.1002/ab.20309

Fuentes, Agustin. 2017. "Human Niche, Human Behaviour, Human Nature.” Interface Focus 7: 20160136. doi: 10.1098/rsfs.2016.0136.

Geary, David. C. 2000. "Evolution and Proximate Expression of Human Paternal Investment.” Psychological Bulletin 126 (1): 55-77. doi:10.1037/0033-2909.126.1.55.

Geary, James. 2018. “Making Dad Jokes is, in Fact, a Neurological Condition.” Literary Hub, December 18, 2018. https://lithub.com/making-dad-jokes-is-in-fact-aneurological-condition/.

Gervais, Matthew, and David Sloan Wilson. 2005. "The Evolution and Functions of Laughter and Humor: A Synthetic Approach.” The Quarterly Review of Biology 80 (4): 395 430. doi:10.1086/498281.

Google. 2020. “Google Books.” Accessed November 25, 2020. https://books.google.dk/. Gray, Peter. 2009. "Play as the Foundation for Hunter-Gatherer Social Existence." American Journal of Play 1 (4): 476-522.

https://www .journalofplay.org/sites/www.journalofplay.org/files/pdf-articles/1-4article-hunter-gatherer-social-existence.pdf. 
.2013. “The Educative Value of Teasing.” Psychology Today, January 13, 2013. https://www.psychologytoday.com/au/blog/freedom-learn/201301/the-educativevalue-teasing-0.

Grice, H. Paul. 1975. "Logic and Conversation.” In Syntax and Sematics, Volume 3: Speech Acts, edited by Peter Cohle and Jerry L. Morgan, 41-58. New York: Academic Press. Hempelmann, Christian F., and Tristan Miller. 2017. "Puns: Taxonomy and Phonology.” In The Routledge Handbook of Language and Humor, edited by Salvatore Attardo, 95108. New York, NY: Routledge.

Henrich, Joseph. 2020. The WEIRDest People in the World: How the West Became Psychologically Peculiar and Particularly Prosperous. New York, NY: Farrar, Straus and Giroux.

Hofmann, Jennifer, Tracey Platt, Chloé Lau, and Jorge Torres-Marín. 2020. “Gender Differences in Humor-Related Traits, Humor Appreciation, Production, Comprehension, (Neural) Responses, Use, and Correlates: A Systematic Review." Current Psychology. doi:10.1007/s12144-020-00724-1.

Hrdy, Sarah Blaffer. 2009. Mothers and Others: The Evolutionary Origins of Mutual Understanding. Cambridge, MA: Harvard University Press.

Hye-Knudsen, Marc, and Mathias Clasen. 2019. “'So-Bad-It's-Good': The Room and the Paradoxical Appeal of Bad Films.” 16:9. http://16-9.dk/2019/11/so-bad-its-good/. Hye-Knudsen, Marc. 2018. "Painfully Funny: Cringe Comedy, Benign Masochism, and NotSo-Benign Violations.” Leviathan: Interdisciplinary Journal in English 2: 13-31. doi:10.7146/lev.v0i2.104693.

Keltner, Dacher. Lisa Capps, Ann M. Kring, Randall C. Young, and Erin A. Heerey. 2001. "Just Teasing: A Conceptual Analysis and Empirical Review." Psychological Bulletin 127 (2): 229-48. doi:10.1037/0033-2909.127.2.229.

Kort, Alicia. 2020. “55 Great Clean Jokes for Funny People Who Don’t Swear.” Fatherly, November 23, 2020. https://www fatherly.com/play/50-great-clean-jokes-for-funnypeople-who-dont-swear/.

Larkin, Bob. 2019. “60 Hysterical ‘Anti-Jokes’ We Can't Stop Reading.” BestLife, July 10, 2019. https://bestlifeonline.com/anti-jokes/.

Larkin, Bob. 2020. “105 Dad Jokes So Bad They're Actually Hilarious.” BestLife, July 31, 2020. https://www.bestlifeonline.com/dad-jokes-so-bad-theyre-actually-hilarious/. 
Lehmann, Julia, Gisela H. Kopp, and Cristopher Boesch. 2006. "Kin Biased Investment in Wild Chimpanzees.” Behaviour 143 (8): 931-955. doi:10.1163/156853906778623635

Luu, Chi. 2019. “The Dubious Art of the Dad Joke.” JSTOR Daily, June 12, 2019. https://daily.jstor.org/the-dubious-art-of-the-dad-joke/.

Martin, Rod A. 2007. The Psychology of Humor: An Integrative Approach. Burlington: Elsevier Academic Press.

Martinez, Angelica. 2020. "18 Punny Jokes That Have No Right to Be as Hilarious as They Are.” BuzzFeed, March 2, 2020. https://www.buzzfeed.com/angelicaamartinez/dadjoke-puns.

McCrae, Robert R., Antonio Terracciano, and 78 Members of the Personality Profiles of Cultures Project. 2005. "Universal Features of Personality Traits from the Observer's Perspective: Data from 50 Cultures.” Journal of Personality and Social Psychology 88 (3): 547-561. doi:10.1037/0022-3514.88.3.547.

McGhee. Paul E. 1979. Humor: Its Origins and Development. San Francisco, CA: W. H. Freeman.

McGraw, Peter A., and Caleb Warren. 2010. "Benign Violations: Making Immoral Behavior Funny.” Psychological Science 21 (8): 1141-9. doi:10.1177/0956797610376073.

Merriam-Webster. 2019. “Dad Joke.” Merriam-Webster's Dictionary. Accessed November 25, 2020. https://www.merriam-webster.com/dictionary/dad\%20joke.

Mitchell, Heidi. 2019. "What Can Science Tell Us About Dad Jokes?" The Wall Street Journal, February 27, 2019. https://www.wsj.com/articles/what-can-science-tell-usabout-dad-jokes-11551278885.

Morreall, John. 2009. Comic Relief: A Comprehensive Philosophy of Humour. Hoboken: Wiley- Blackwell.

Murray, Cason M., Margaret A. Stanton, Elizabeth V. Lonsdorf, Emily E. Wroblewski, and Anne E. Pusey. "Chimpanzee Fathers Bias Their Behaviour Towards Their Offspring." Royal Society Open Science 3 (11): 160441. doi:10.1098/rsos.160441.

Niro, Jimmy. 2018. Dad Jokes! Good, Clean Fun for All Ages! Naperville, IL: Sourcebooks, Inc.

Norton, Jack. 2020. Bad Dad Jokes: Dad Jokes, Redneck Humor, Classic Vaudeville Skits and More! Minneapolis, MA: Norton Family Publishing.

Nowak, Thomas. 2020. The Essential Compendium of Dad Jokes. San Fransisco, CA: Chronicle Books. 
Oxford University Press. "dad, n. 1.” OED Online. Accessed November 25, 2020.

https://www-oed-com.ez.statsbiblioteket.dk:12048/view/Entry/46813.

Paquette, Daniel, René Carbonneau, Diane Dubeau, Marc Bigras, and Richard E. Tremblay. "Prevalence of Father-Child Rough-and-Tumble Play and Physical Aggression in Preschool Children.” European Journal of Psychology of Education 18 (2):171-189. doi:10.1007/BF03173483.

Pelzer, Kelsey. 2020. "Here are the 100 Best Corny Dad Jokes Ever!” Parade, October 1, 2020. https://www.parade.com/940979/kelseypelzer/best-dad-jokes/.

Pickhardt, Carl E. 2013. "Why So Sensitive? Adolescence and Embarrassment.” Psychology Today, October 14, 2013. https://www.psychologytoday.com/gb/blog/surviving-yourchilds-adolescence/201310/why-so-sensitive-adolescence-and-embarrassment.

Pinker, Steven. 2008. The Stuff of Thought: Language as a Window into Human Nature. New York: Penguin Books.

Polimeni, Joseph, and Jeffrey P. Reiss. 2006. “The First Joke: Exploring the Evolutionary Origins of Humor.” Evolutionary Psychology 4 (1): 347-66. doi:10.1177/147470490600400129.

Provine, Robert. 2000. Laughter: A Scientific Investigation. London: Penguin Books. Raskin, Victor. 1992. "Humor as a Non-Bona-Fide Mode of Communication." Deseret Language and Linguistic Society Symposium 18 (1): 87-92.

Reddit. 2020. "R/DadJokes - The Best Dad Jokes on Reddit.” Accessed November 25, 2020. https://www .reddit.com/r/dadjokes/.

Redfern, Walter D. 2000. Puns: More Senses Than One. London: Penguin.

Ritchie, Graeme D. 1999. "Developing the Incongruity-Resolution Theory.” Proceedings of AISB Symposium on Creative Language: Stories and Humor, Edinburgh, April 1999, 78-85. https://homepages.abdn.ac.uk/g.ritchie/pages/papers/aisb99.pdf.

Romas, Bethany. 2014. “15 Stupid-Funny Dad Jokes You Can Use To Embarrass Your Kids.” Mommyish, April 7, 2014. https://www.mommyish.com/2014/04/07/dadjokes/.

Semrud-Clikeman, Margaret, and Kimberly Glass. 2010. "The Relation of Humor and Child Development: Social, Adaptive, and Emotional Aspects.” Journal of Child Neurology 25 (10):1248-60. doi:10.1177/0883073810373144.

Shibles, Warren A. 1997. Humor Reference Guide: A Comprehensive Classification and Analysis. Carbondale, IL: Southern Illinois University Press. 
Shifrin, Joshua. 2018. Dad Jokes: The Good, the Bad, and the Just Plain Stupid. Scotts Valley, CA: CreateSpace Independent Publishing Platform.

Shultz, Thomas R., and Frances Horibe. 1974. "Development of the Appreciation of Verbal Jokes." Developmental Psychology 10 (1): 13-20. doi:10.1037/h0035549.

Simler, Kevin, and Robin Hanson. 2017. The Elephant in the Brain: Hidden Motives in Everyday Life. Oxford: Oxford University Press.

StGeorge, Jennifer, and Emily Freeman. 2017. "Measurement of Father-Child Rough-AndTumble Play and Its Relations to Child Behavior.” Infant Mental Health Journal 38 (6): 709-725. doi:10.1002/imhj.21676.

Tokunbo, Okafur. 2019. “50 Funny Dark Jokes and Puns.” Legit. Accessed November 30, 2020. https://www.legit.ng/1254935-50-funny-dark-jokes-puns.html.

Tomasello, Michael. 2011. The Origins of Human Communication. Cambridge, MA: MIT Press.

Urban Dictionary. 2020. “Dad Joke.” Urban Dictionary. Accessed November 25, 2020. https://www.urbandictionary.com/define.php?term=Dad\%20Joke.

van Hoof, Jan A. R. A. M. 1972. "A Comparative Approach to the Phylogeny of Laughter and Smiling.” In Non-Verbal Communication, edited by Robert A. Hinde, 209-241. Cambridge: Cambridge University Press.

Veatch, Thomas C. 1998. “A Theory of Humor.” Humor: International Journal of Humor Research 11(2), 161-215. doi:10.1515/humr.1998.11.2.161.

Warren, Caleb, \& A. Peter McGraw. 2016. "Differentiating What Is Humorous from What Is Not.” Journal of Personality and Social Psychology 110 (3): 407-30. doi:10.1037/pspi0000041.

Webber, Forest. 2020. “The Big List of the Funniest Dad Jokes.” everythingMOM, March 12, 2020. https://www .everythingmom.com/parenting/dad-jokes.

Weisberg, Yanna J., Colin G. DeYoung, and Jacob B. Hirsh. 2011. “Gender Differences in Personality across the Ten Aspects of the Big Five." Frontiers in Psychology 2: 178. doi:10.3389/fpsyg.2011.00178.

Wiseau, Tommy, dir. 2003. The Room. Los Angeles, CA: Wiseau-Films.

Zinoman, Jason. 2019. “A Dad Defends Dad Jokes” The New York Times, June 12, 2019. https://www.nytimes.com/2019/06/12/arts/television/dad-jokes.html. 